\title{
Neuro-Didactics and Social Sciences: An Experience of the Application of DAS Sequence in the Geography Classroom ${ }^{+}$
}

\author{
Mario Corrales Serrano 1,*, José Moreno Losada ${ }^{1}$, Jesús Sánchez Martín ${ }^{2}$ and \\ Francisco Zamora Polo ${ }^{3}$ \\ 1 Departamento de Didáctica de las Ciencias Sociales, las Lenguas y las Literaturas. Facultad de Educación, \\ Universidad de Extremadura, 06071 Badajoz, Spain; jmorenol@unex.es \\ 2 Departamento de Didáctica de las Ciencias Experimentales y las Matemáticas, Facultad de Educación, \\ Universidad de Extremadura, 06071 Badajoz, Spain; jsanmar@unex.es \\ 3 Departamento de Ingeniería Mecánica, Energética y de los Materiales. Escuela de Ingenierías Industriales, \\ Universidad de Extremadura, 06071 Badajoz, Spain; fzamora@unex.es \\ * Correspondence: mariocorralesserrano@gmail.com; Tel.: +34-674964987 \\ + Presented at the 2nd Innovative and Creative Education and Teaching International Conference \\ (ICETIC2018), Badajoz, Spain, 20-22 June 2018.
}

Published: 26 October 2018

\begin{abstract}
One of the points of attention of didactics in recent times is the application of knowledge that comes from neuroscience. Knowing how the human brain works and how it learns is a valuable knowledge for the design of effective didactic strategies. The present work is the result of a simple application of some of basic principles of functioning of the human brain to the design of a didactic strategy in the area of Social Sciences, and more specifically, in the field of the Geography. This strategy has been applied in crossed groups with the same academic level, with the purpose of being able to compare learning results of the same contents with different methodologies. The preliminary results suggest that there is a greater use of the knowledge inculcated when it is applied a specific didactic pattern based on neuro-education. Despite the limitation of the small number of participants in the study, this is useful as a first experience in these innovative methodologies.
\end{abstract}

Keywords: didactic; social sciences; neuro-education

\section{Introduction}

The search for motivational strategies in the development of any didactic experience is one of the objectives of any teacher. Some studies that we have done previously indicate that in the teaching of Social Sciences is more important, if possible, the challenge posed by motivation, both intrinsic and extrinsic, to obtain better didactic results [1].

In the teaching of the different educational disciplines, the results of neuroscientific studies, which offer information about the way the brain acts in a motivating experience, are being increasingly incorporated. In this report, we present a concrete experience on the application of the postulates of neuroscience in a didactic intervention in the area of Geography, in Compulsory Secondary Education (specifically, in the 1st year). The main objective of our work is to verify if the design of a teaching unit taking into account the sequence DAS (-Dopamine/Adrenaline/Serotoninas main neurotransmitters that are generated in the process of motivation in the brain), provokes some type of incidence in the motivation of the students of this subject in order to learn the same [2]. 
Some recent studies on the functioning of the brain and its application in education describe a motivational process, which some call "brain circuits of motivation." Following this descriptive model we could talk about three phases that occur at the brain level in a motivation process (Figure 1):

1. -Initial phase, in which the necessary conditioning factors are generated so that the motivation arises (intrigue, curiosity, awakening of attention centers). Dopamine is the neurotransmitter responsible for generating this situation at the brain level.

2. -Phase of action, in which our personal resources are put in place to respond to the initial stimulus. In this phase the adrenaline acts like "gasoline", so that our brain puts us in action.

3. -Final phase, which takes place when we get the reward, the learning or resolution of the initial challenge. At this time, serotonin causes a sensation of tranquility and calm, in response to the success of the objective achieved.

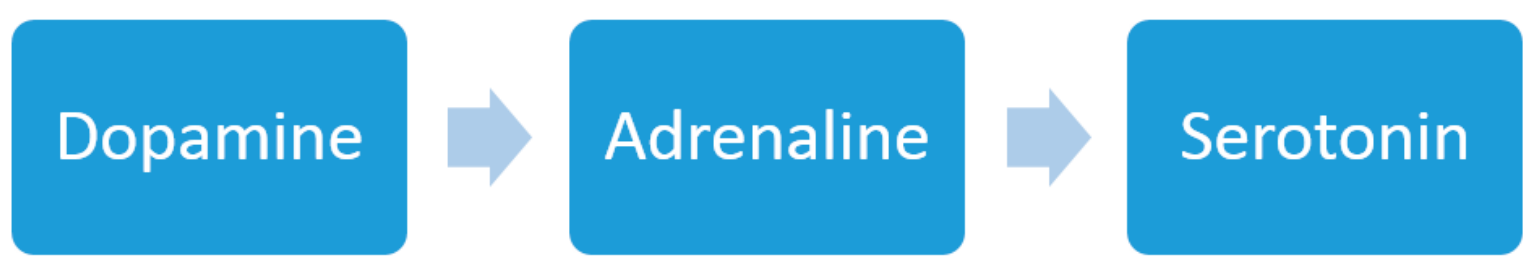

Figure 1. DAS sequence.

This sequence, known by some authors about neuro-education as "DAS sequence", can offer us a very useful pattern in the design of the teaching-learning activity. Our hypothesis is based on the fact that, if we propose a didactic strategy taking into account this brain circuit of motivation, we increase our chances of success in the task of motivating students.

\section{Experimental Phase}

The experience that we have carried out is the development of a block of contents and competences of a didactic unit of the subject Geography, of the 1st year of Compulsory Secondary Education. The specific teaching unit chosen is "Landscapes of the Earth", which allows us to work different blocks independently. One of the blocks of content has been subjected to a didactic design under the parameters of the motivational circuit described in the principles of neuro-didactics (DAS) [3]. It is important to note that we have only designed one block of the teaching unit to be able to contrast the learning results of that part with those of the other parts of the subject. The design responds to the next structure:

Phase 1 (Start): instead of presenting the students with a type of landscape, we present a video of a character, who tells them that he lives in a place in the world where there is a landscape with certain characteristics, and he asks them a double question: What area of the world is it? What landscape is it?

Phase 2 (Action): Using the book and the didactic material, students should look for the answer to the double question of the character of the video, and also justify their response.

Phase 3 (Final): Those students who succeed in matching the right landscape and world zone are awarded with a prize in the form of didactic reinforcement.

The intervention is carried out in two groups of 1st year ESO (26 and 28 students respectively), developing with the DAS sequence different parts of the subject in each group, (Mediterranean landscape in group A and desert landscape in group B) so that we can cross the results in both groups and be able to see the real incidence of the motivational strategy applied. 


\section{Results}

To evaluate the results we have used three different procedures:

- Observation of the results obtained in the objective test of the end of the unit, to contrast the possible differences present in the results referring to the parts that have been developed with a traditional way and those that have been implemented with the DAS sequence. (Quantitative reading of the data).

- Observation of the notes that have been obtained in the daily learning program of the subject in a selection of students, to be able to appreciate how they refer to the learning of the different parts of the didactic unit. (Qualitative reading of the data, interpreted with WebQDA) [4].

- Results obtained in the review questionnaire, differentiated according to the different parts of the unit. (Quantitative reading of the data and qualitative).

\section{Conclusions}

When crossing the results of these three procedures used, we observed that, in this specific experience, the application of the sequence of motivation based on the neuro-didactic generates better academic results and with a greater predisposition of the students for the learning of the subject, although it would be necessary to introduce other contrast elements so that these results can be universalized.

It is true that the small number of participants in the experience, the lack of other complementary experiences that could help us to consolidate the results over time, and the fact that we are not experts in this area, do not allow us to draw conclusions beyond the experience described. However, this may be useful as a starting point for further research in this same field of study.

\section{References}

1. Corrales, M.; Sánchez, J.; Moreno, J. The motivation in the teaching of social sciences at the High School: NOVA. J. Educ. Res. 2016, 10, 181.

2. Blakemore, S.J.; Frith, U.; Marina, J.A. Cómo Aprende el Cerebro. Las Claves para la Educación; Ariel: Barcelona, Spain, 2007; p. 26.

3. Gerhard, F.; Gerhard, P. Neurodidáctica. Mente y Cerebro 2003, 4, 39-45.

4. Costa, A.; Moreira, A.; Neri de Souza, D.; Freitas, F. WebQDA. Manual de Utilización Rápida; University of Aveiro: Aveiro, Portugal, 2016. 